\title{
Cristiandad y Cristianismo: dos proyectos para la evangelización
}

\author{
Juan Pablo ARANDA ${ }^{1}$ \\ Universidad Popular Autónoma del Estado de Puebla (México) \\ juanpablo.aranda@upaep.mx
}

\section{RESUMEN}

En este artículo comparo la aplicación de la perspectiva evangelizadora denominada «Cristiandad» en el Nuevo Mundo, por un lado (I), y la labor misionera del jesuita Matteo Ricci en China, por el otro (II), enfatizando los fundamentos teológico-metafísicos que sustentaron cada empresa. Asimismo, propongo que la idea de «unidad a través de la diferencia» de Charles Taylor, así como la epistemología «posconciliar» de Joseph Ratzinger, ofrecen un marco interpretativo de la transición desde un catolicismo autoritario a uno basado en la conciencia y la responsabilidad (III).

Palabras clave: Autoridad, conciencia, posconciliar, diferencia, naturaleza.

\section{Christendom and Christian faith: two evangelization projects}

\begin{abstract}
In this article I compare the enforcement of the evangelizing perspective called «Christendom» in the New World, on one side (I), and Matteo Ricci's mission in China, on the other (II), emphasizing the theological and metaphysical justifications of each project. I also propose that Charles Taylor's idea of «unity-through-difference», as well as Joseph Ratzinger's «postconciliar» epistemology, offer an interpretative framework for the translation from an «authoritarian» Catholicism to one based on conscience and responsibility (III).
\end{abstract}

Keywords: Authority, conscience, postconciliar, difference, nature.

SUMARIO: 1. Cristiandad: Sepúlveda y Las Casas. 2. Cristianismo: Matteo Ricci en China. 3. Después del Concilio Vaticano II: Ratzinger y Taylor. 4. Bibliografía.

FECHA DE RECEPCIÓN: 27 DE 03 DE 2014

FECHA DE ACEPTACIÓN: 20 DE 06 DE 2014

\footnotetext{
${ }^{1}$ Mi profundo agradecimiento a Juan Pablo Salazar Andreu y Jorge Medina Delgadillo, quienes hicieron importantes aportaciones al manuscrito, así como a mi asistente de investigación, Valeria Quevedo. Igualmente agradezco los comentarios y observaciones de los lectores anónimos.
} 


\section{CRISTIANDAD: SEPÚLVEDA Y LAS CASAS}

El descubrimiento del Nuevo Mundo constituye uno de los puntos de inflexión históricos más importantes de la aventura humana. La empresa de Cristóbal Colón encuentra una bella representación en El sueño de Cristóbal Colón, de Dalí: sueño augusto de una Iglesia jerárquica entronizando una tierra virgen en su seno, la cruz de Cristo dominando el horizonte, dibujado él mismo sobre un tapiz de finas cruces y, rostro al suelo, el fraile que se aferra a la cruz en la soledad de lo inhóspito y salvaje $^{2}$. Resulta peculiar el juego del pintor con la desnudez: a la izquierda el ejército divino ataviado con palio y mitra; a la derecha el hombre, en su original desnudez, pero coronado con armas y banderas, con la identidad nacional, como si la desnudez fuera grotescamente ilusoria, brutalmente imposible en el baile entre conquistador y conquistado. De entre las armas asoma, finalmente, Jesús crucificado, quizá un desgarrador recordatorio de que, en la historia, los idilios no existen.

La España católica recibió, el 4 de mayo de 1493, de manos del Papa Alejandro VI -entonces no sólo líder espiritual, sino fuerza política omnipresente en un continente que renacía de la mano de la incipiente ciencia moderna- la bula Inter caetera, en la que se le «concedía» buena parte de las tierras recién descubiertas, a efecto de llevar el mensaje de Cristo a tierras lejanas y hacer germinar la flor del cristianismo.

La presión de frailes como Bernardino de Minaya ${ }^{3}$, Antonio de Montesinos ${ }^{4} \mathrm{y}$ Bartolomé de las Casas, por citar sólo a algunos, obligó a Carlos V -en un hecho inédito en la historia que atestigua la sensibilidad española respecto de la evangelización- a suspender, en abril de 1550, las conquistas en ultramar hasta que una junta de especialistas se pronunciara sobre la justicia de dicha empresa ${ }^{5}$. Fue en este marco que se produjo el enfrentamiento entre el jurista Juan Ginés de Sepúlveda y el explosivo fraile dominico, defensor de los derechos del indio, Bartolomé de Las Casas. Trataré de mostrar que desde las entrañas de este debate transpira el aroma de aquel proyecto evangelizador denominado «Cristiandad».

Juan Ginés de Sepúlveda fue cronista oficial de Carlos I y Felipe II, jurista e historiador, y recibió el encargo del entonces púrpura, Julio de Médecis (luego Cle-

\footnotetext{
${ }^{2}$ Ratzinger recuerda el Zapato de Raso, de Paul Claudel para expresar esta sensación dialéctica de cercaníalejanía que atribuye al sentimiento religioso contemporáneo. El misionero, capturado por piratas y atado a un madero, habla a Dios: «...hoy no hay manera de estar más apretado con vos que lo que estoy... Verdad que estoy atado a la cruz, pero la cruz no está atada a soporte alguno. Flota en el mar». Resulta interesante el paralelismo entre la sensación de aislamiento del fraile evangelizador en la América virgen y el católico contemporáneo enfrentado a un mundo inhóspito que le desconoce y desconfía de él (Ratzinger 2001, 43).

3 «En $1536 \ldots$ [Minaya] realiza su viaje a Europa, para solicitar la intervención pontificia en los asuntos americanos, concretamente en defensa de los indios». (De la Hera, 1992, 115). En la carta que dirige a Felipe II, el fraile atestigua la brutalidad española: «yo he estado diez años en las Indias de V.M. y he visto las tiranías que los españoles hacen en los indios que a Dios quitan las ánimas y a V.M. los vasallos», (Hanke, 1992, 85).

${ }^{4}$ «En el año de 1511, el dominico fray Antonio de Montesinos denuncia, desde el púlpito, el sistema de encomiendas y los malos tratos de que los indios eran constantemente víctimas». (De la Hera, 1992 99).

${ }^{5}$ «Probably never before or since has a mighty emperor -and in 1550 Charles V was the strongest ruler in Europe with a great overseas empire besides-in the full tide of his power ordered his conquests to cease until it could be decided whether they were just». (Hanke, 1949, 117).
} 
mente VII), de traducir las obras completas de Aristóteles. Se enfrentó a Erasmo de Rotterdam -fuerte crítico de la imposición de la fe por medio de las armas ${ }^{6}$ - en su Gonsalus, afirmando la compatibilidad entre el espíritu militar y el cristianismo y aduciendo que «las guerras son una ocasión inmejorable para practicar una serie de virtudes que, en época de paz, difícilmente pueden ejercitarse» ${ }^{7}$. En 1550 se enfrentó a Bartolomé de las Casas respecto de la justicia o injusticia de las conquistas llevadas a cabo por España en territorio indiano.

En su Democrates alter presentó Sepúlveda su justificación de la guerra española apoyándose en cuatro causas: (i) la servidumbre natural de los indios; (ii) la obligación de eliminar aberraciones morales como la antropofagia y los sacrificios humanos; (iii) proteger a las víctimas de sendos crímenes; y (iv) la promoción del cristianismo ${ }^{8}$.

En cuanto a la primera causa, dice Sepúlveda que es válido «someter con las armas, si por otro camino no es posible, a aquellos que por condición natural deben obedecer a otros y rehúsan su imperio» ${ }^{9}$. Esta idea se encuentra apoyada en la doctrina aristotélica de la servidumbre natural, según la cual «aquel que por naturaleza no es dueño de sí mismo, siendo él mismo un hombre, es un esclavo por naturaleza» (1254a). Este binomio servidumbre-autoridad se origina en el nacimiento, primero, porque la naturaleza dota a algunos de las herramientas para mandar, y a otros, aquéllas para servir; $\mathrm{y}$, segundo, puesto que «donde existe una diferencia tal como aquélla entre alma y cuerpo, o entre hombres y animales [...] la categoría inferior es por naturaleza esclava, y es mejor para éstos, al igual que para toda criatura inferior, encontrarse bajo la autoridad del amo» ${ }^{10}$.

La bula Sublimis Deus del Papa Pablo III, signada el 2 de junio de 1537, debilitará el argumento aristotélico enfatizando la dignidad humana de los naturales de las tierras recién descubiertas y obligando a los conquistadores a respetar a los aborígenes en sus libertades y propiedades. Más importante resulta la prohibición de la servidumbre, así como la modalidad particular de dicha evangelización: «deben ser invitados a abrazar la fe de Cristo». Con esta bula quedaba desarmado el argumento sobre la servidumbre natural ${ }^{11}$. Asimismo, la cuarta consideración, sobre la expan-

\footnotetext{
${ }^{6}$ Erasmo (1917, p. 56) aboga por la tolerancia, el respeto y la razón: «it were far better to allure him [the Turk] by gentle, kind, and friendly treatment, by exhibiting the beauty of our Christian religion in the innocence of our lives, than by attacking him with the drawn sword, as if he were a savage brute, without a heart to feel, or a reasoning faculty to be persuaded». En Enchiridion, por su parte, presenta el conocimiento como el distintivo de los hijos de Dios: «But they who say, Depart from us, for we desire not the knowledge of thy ways, will be abandoned by the divine mercy, because they hated knowledge». Cfr. Lc 9:1-5.

7 Espigares, 1993, 187.

8 Cfr. Maestre, 2004, 117-130; Hanke, 1949, 120; Manero, 2009, 96.

9 Sepúlveda, 1987, 81. (Cursivas mías).

${ }^{10}$ Aristóteles, La Política, Libro Primero. Cf. Platón, La República, 590d.

${ }^{11}$ Hanke, no obstante, refiere el Breve que el Papa Paulo III redactara el 19 de junio de 1538, por el que se revocaban «todos los otros breves o bulas promulgados con anterioridad que resultasen en perjuicio del poder del Emperador Carlos V como Rey de España y que pudieran perturbar el buen gobierno de las Indias». Aunque, en opinión del historiador, el Breve no parece referirse a la Sublimis Deus, «de todos modos el
} 
sión del cristianismo, quedaba delimitada y excluía la guerra como mecanismo para su ejecución. Esta idea se encuentra en línea, asimismo, con el texto joánico (Ap $3: 20)^{12}$.

Ahora bien, por lo que hace a las otras dos consideraciones, (ii) y (iii), vemos que, en realidad, implican un solo problema observado desde la perspectiva del mal que debe combatirse, por un lado, y la protección de las víctimas de dicho mal, por el otro. Sepúlveda se apoya, para justificar la guerra, en el relato del diluvio (Gen, 6), la destrucción de Sodoma y Gomorra (Gen, 19), el Emperador Constantino, y San Gregorio, quien «alaba en una de sus epístolas a Gennadio, gobernador de África que perseguía a los paganos por causa de religión $»^{13}$. Así, es a partir de la tradición veterotestamentaria y de la historia de la Iglesia naciente como Sepúlveda concluye que «no es doctrina temeraria [...] el ser lícito a los cristianos perseguir a los paganos y hacerles guerra si no observan la ley natural» ${ }^{14}$. Lo anterior, debe enfatizarse, con la intención no de entronizar el cristianismo en el alma pagana, sino al menos de «atajar sus maldades» ${ }^{15}$.

Resulta interesante retomar aquí el pensamiento del teólogo tomista, Francisco de Vitoria, en relación con estas consideraciones. En la producción del dominico encontramos, entremezclados, vestigios del proyecto autoritario, lo mismo que evidentes desarrollos humanistas ${ }^{16}$. Me referiré aquí a dos aspectos que serán cardinales para el proyecto de la Cristiandad: (i) su concepción de la primacía de la autoridad sobre la conciencia; y (ii) la idea de la ley natural como fundamento de la moral.

En la primera relección del De indis, Vitoria establece que: «en las cosas que a la salvación miran, obligación hay de creer a los que la Iglesia puso para enseñar» ${ }^{17}$. Ahora bien, cuando existe duda fundada respecto de algún artículo relacionado con la salvación, Vitoria asigna a la opinión de los «sabios» una función suplementaria de forma tal que, una vez emitida, «hay que atenerse» a ella, incluso al grado de que, si los sabios sentenciaran una obra ilícita como lícita, quien obrara siguiendo su opinión lo haría «con seguridad de conciencia» ${ }^{18}$. La conciencia queda, pues, supeditada a la

Emperador parece haber entendido que en aquel breve se revocaban todas las bulas y los breves», lo que sin duda habría debilitado su eficacia. (Hanke, 1992, 55-61).

12 Incluso en la dureza que muestra Mt 10:14-15, respecto de la evangelización - «y si no los reciben ni quieren escuchar sus palabras, al irse de esa casa o de esa ciudad, sacudan hasta el polvo de sus pies; les aseguro que, en el día del Juicio, Sodoma y Gomorra serán tratadas menos rigurosamente que esa ciudad»- la tarea del apóstol se limita al anuncio del Reino; la negativa no da pie a la imposición, sino que suspende el juicio sobre aquellos «de corazón duro» (Ex 8:15, Ez 11:19, Mt 13:15) hasta el fin de los tiempos, esto es, Dios mismo se reserva el derecho de juicio.

13 Sepúlveda, 1987, 121.

14 Sepúlveda, 1987, 121.

15 Sepúlveda, 1987, 127.

16 Vitoria, por ejemplo, delimitará con claridad y honda inteligencia el poder temporal y espiritual: negará al Papa poder temporal sobre los bárbaros del Nuevo Mundo; y, asimismo, declarará que la infidelidad y el pecado no impiden la capacidad para el señorío político (Vitoria, 1974, 33ss.).

17 Vitoria, 1974, 25.

18 Vitoria, 1974, 27. 
voz del sabio, estableciéndose así una jerarquía teológica por mandato divino entre quienes comprenden e interpretan y quienes obedecen sin comprender ${ }^{19}$.

Esta jerarquía, originalmente teológica, fue deformada por el proyecto histórico que Taylor llama Cristiandad (ver apartado III), a saber, aquel originado a partir del matrimonio entre una fe y una concepción social: la evangelización de la Nueva España será un terreno de enfrentamiento entre esta perspectiva anacrónica, basada en la autoridad, y un naciente celo renacentista, humanista y republicano ${ }^{20}$. A través de dicha deformación, pues, lo teológico fue arbitraria y sigilosamente desdoblado en jerarquía social. Emergió la categoría de «ciudadanos inferiores» exentos incluso del adecuado uso de su razón. El principio jerárquico, originalmente teológico, debía inundar la estructura social, transformándola y ajustándola a su propia lógica, esto es, imponiendo una estratificación artificial que descansara, en última instancia, en la elongación desmedida de dicha teología. Esta sociedad, una vez enderezada y encasillada en el paradigma vertical, clausuraría lo que para Kant será, dos siglos después, apenas el inicio de la madurez humana: esto es, la liberación individual de estructuras de autoridad que impiden, en su operación, el libre florecimiento de la conciencia ${ }^{21}$. Por supuesto, tal como dije anteriormente, dicho proyecto encontró la resistencia de una multiplicidad de frailes, filósofos y eruditos que lucharon por construir, en América, lo que en Europa parecía nada más que utopía y absurdo.

En cuanto a la ley natural, Vitoria se apoya en el pensamiento tomista, aduciendo que ésta es cognoscible, al menos como posibilidad, por todo individuo ${ }^{22} \mathrm{y}$, asimismo, aplicable como base moral universal. La guerra es justificada por la ley natural, «pues no son en esto dueños de sí mismos, ni alcanzan sus derechos a entregarse ellos a la muerte ni a entregar a sus hijos» ${ }^{23}$. Como si deseara totalizar la máxima legal, ignorantia juris non excusat, Vitoria inscribe -a partir de su comprensión del tomismo- la ley natural en el intelecto/espíritu humano y cancela la posibilidad de una ignorancia invencible de la misma de parte del individuo, considerándolo, al mismo

19 Ver De Aquino (II-IIae, c.104): «lo normal en la naturaleza es que los seres superiores muevan a los inferiores a realizar sus acciones mediante el poder natural superior que Dios les dio. Por lo que es normal también que en la actividad humana los superiores muevan a los inferiores mediante su voluntad, en virtud de la autoridad establecida por Dios»».

${ }^{20}$ Es importante notar que la historia de evangelización en América muestra innumerables ejemplos de auténtico humanismo y fervor republicano que nada compartían-e, incluso, se enfrentaban-con el proyecto unificador al que me refiero en este escrito: «No obstante su promisorio futuro en la Universidad de Salamanca, Alonso Gutiérrez, fiel a los valores del renacimiento humanístico español, decidió venir a la Nueva España en 1536, para promover entre los indígenas los estudios humanísticos y el evangelio, pero sobre todo para realizar los ideales humanísticos del Renacimiento» (Velasco, 2007, 51-55).

21 Kant, 1979.

22 Tomás de Aquino, no obstante, reconoce grados de conocimiento de la ley natural: «si hablamos de las conclusiones particulares de la razón especulativa, la verdad es la misma para todos los hombres, pero no todos la conocen igualmente» (I-IIae, 94, a.5); asimismo, que la ley natural es inmutable sólo en lo que se refiere a los primeros principios, pero «puede cambiar en algunos casos particulares y mayoritarios por motivos especiales, que impiden la observancia de tales preceptos» (I-IIae, 94, a.5). La Cristiandad parece haber ignorado estas sutilezas en el pensamiento tomista.

23 Vitoria, 1974, 69. 
tiempo, suficientemente transparente a sí mismo como para garantizar la posibilidad de dicho acceso a la ley.

Debe recordarse, empero, que esta ley, compartida por los corazones humanos, termina siendo mediada, como se discutió arriba, por el sabio, que en última instancia subsiste como garante de la correcta interpretación de dicha ley. El individuo, al final, queda encasillado entre una ley absolutamente transparente para sí pero que, no obstante, requiere un proceso de filtrado del que (se asume) es incapaz. Aparece aquí una evidente contradicción: si la ley es transparente, no se comprende la necesidad de sabios o mediadores; y, si no lo es, entonces dicha ley difícilmente puede prestar el servicio que Sepúlveda y Vitoria le asignan.

Las Casas se opuso vigorosamente a Sepúlveda mostrando un rostro indio (al parecer, exageradamente) lleno de virtudes ${ }^{24}$ - «Todas estas universas e infinitas gentes, a totó genere crió Dios las más simples, [...] más humildes, más pacientes, más pacíficas y quietas, sin rencillas ni bullicios, no rijosos, no querulosos, sin rencores, sin odios, sin desear venganza» $\rangle^{25}$; fervoroso - «nunca gente hobo en el mundo de cuantas habemos nombrado [...] que tan religiosa y devota fuere» ${ }^{26}$; y civilizado - «la casa real donde Montezuma ordinariamente vivía era cosa admirable ver su grandeza, salas, retraimientos altos y bajos, aposentos y puertas y edificios y todas cosas muy notables» ${ }^{27}$. De acuerdo con el fraile, los españoles debían ser detenidos a fin de evitar que las agresiones ${ }^{28}$ contra los naturales siguieran.

Las Casas pretendió desarmar la primera justificación de Sepúlveda descomponiendo la doctrina aristotélica en cuatro clases de «barbarie» ${ }^{29}$ : (i) bárbaros en sentido impropio y amplio; (ii) aquéllos que carecen de un idioma literario que les permita expresar lo que piensan; (iii) bárbaros en sentido propio y estricto, esto es, hombres crueles, feroces, estólidos, estúpidos y ajenos a la razón; y (iv) los hombres que no conocen a Cristo. Mientras que su oponente ubicaba a los indios en la tercera clase, el dominico afirma que éstos sólo podían alinearse a la cuarta categoría que, vale añadir, caía perfectamente en una de las conclusiones de Vitoria respecto de la guerra justa, a saber, que «la infidelidad no es impedimento para ser verdadero señor» ${ }^{30}$.

\footnotetext{
${ }^{24}$ Levillier critica la generalización del fraile. Refiriéndose a los indios, indica: «Their intelligence, cruelty, and meekness varied as did the color of their skins, their languages, their rites... Neither in their juridical position, in their physical aspect... nor in their creative capacities were they alike». (Citado en Hanke, 1949, 128). Alvear $(1992,16)$ recuerda que el medievalista español, Ramón Menéndez Pidal, «quiso destacar las exageraciones que... especialmente en su célebre opúsculo, Brevísima relación de la destrucción de las indias, acumuló invectivas y denuncias tales, que los enemigos de España y del Catolicismo aprovecharon, entre otros materiales, para la formación de la "leyenda negra"».

${ }^{25}$ Las Casas, 1941, 17. «Parábanse a mirar los cristianos a los indios, no menos maravillados que los indios dellos, cuánta fuese su mansedumbre, simplicidad y confianza de gente que nunca cognoscieron». (Las Casas, 1951, 202).

${ }^{26}$ Las Casas, 2004, 109.

27 Las Casas, 2004, 9.

28 Sahagún da muestras de la violencia española, (1999, 738).

29 Maestre, 2004, 119.

30 Vitoria, 1974, 30.
} 
Este deslizamiento estratégico no debe llevarnos a olvidar que, al hacer uso de dicha tipología, Las Casas aceptaba tácitamente la autoridad del estagirita y, por ende, la existencia de la servidumbre natural. De la Hera informa, en efecto, que Juan de Zumárraga «poseyó esclavos negros, aquellos mismos esclavos que Las Casas quiso importar alguna vez para librar a los indios de la esclavitud» ${ }^{31}$. Las Casas se limita a la defensa de un grupo -no del «hombre»-alegando errores en la categorización de los indios, sin distanciarse de la jerarquía natural aristotélica. El principio jerárquico, pues, subsiste, aunque quizá la cuerda de su arco se ha destensado un poco, permitiendo ciertas valorizaciones e interpretaciones, pero en ningún momento ha quedado eliminado.

Contra las demás justificaciones aducirá el fraile la regla general de que los príncipes cristianos sólo pueden iniciar una guerra por causas defensivas, esto es, a fin de repeler ataques injustificados del enemigo. Ahora bien, en tanto los naturales del recién descubierto continente no habían sido los iniciadores del conflicto, se sigue la imposibilidad de entablar una guerra justa contra éstos ${ }^{32}$. Esta idea empata, asimismo, con la sentencia de Vitoria según la cual «no se puede usar de las armas contra quienes no nos hacen mal, ya que por derecho natural está prohibido matar a inocentes» ${ }^{33}$. De aquí que Las Casas argumentara, reporta Manero, «que el remedio de la guerra causaría males mayores [...]. Lo que era necesario era un cambio de religión [el cual] no podía imponerse por la fuerza, sino que debía caracterizarse por ser una tarea evangelizadora que, desde el respeto a los pueblos que allí habitaban, consiguiera la cristianización de las Indias».

El padre Las Casas construyó una defensa del indio apoyado en al menos tres herramientas: (1) el elemento empírico, esto es, la cuidadosa relatoría de las costumbres y actitudes indias-del que es ejemplo su Apologetica Historia-, a fin de rechazar las acusaciones de barbarie e incultura contra los naturales; (2) una discusión filosófica sobre la base del pensamiento aristotélico, del que Sepúlveda había echado mano; y (3) una defensa teológica apoyada en lo establecido en la bula Sublimis Deus, de Pablo III. No hay duda, finalmente, que fray Bartolomé se apoyaba, al igual que Sepúlveda y Vitoria, en la doctrina de la ley natural, entonces dominante en el imaginario cristiano. Sobre la educación de los servidores en los templos, por ejemplo, comenta que «estos eran doctrinados por el maestrescuela [...] para que huyesen los vicios, según la estimación que ellos podían tener de la virtud por la lumbre de la razón natural» ${ }^{34}$.

Que Las Casas recurriera a la filosofía aristotélica y a la ley natural implica que, aun cuando criticara -justamente- los excesos de los españoles cometidos contra los indios, su cosmovisión no difería drásticamente de la de aquellos a quienes denunciaba: confesaba un universo jerarquizado natural y teológicamente que Charles Taylor,

\footnotetext{
31 De la Hera, 1992, 111.

32 Ver Suma Teológica, II-IIae, c.64.

33 Vitoria, 1974, 82.

34 Las Casas, 2004, 92.
} 
de quien nos ocuparemos en la tercera sección, denomina «Christendom». Me parece, como he dicho, que esta cosmovisión es compartida tanto por Sepúlveda como por el fraile Las Casas, y que la disputa a la que se ha hecho referencia no pretendió en ningún momento cuestionar o criticar dicha cosmovisión, sino atemperar, en todo caso, sus más violentas manifestaciones.

\section{CRISTIANISMO: MATTEO RICCI EN CHINA}

Jaime Ruiz de Santiago relata la aventura misionera del jesuita Pedro Páez en Etiopía, la cual comparte, en muchos aspectos, el espíritu de la misión que Matteo Ricci realizó en China. Ordenado en 1589, Páez se dirigió casi de inmediato a Etiopía junto con Antonio de Montserrat, donde poco después caerían presos de los turcos, reducidos a servidumbre y regalados al sultán árabe de Xae ${ }^{35}$. Liberados gracias al rescate pagado por Felipe II, los caminos de los misioneros se separarían debido a la muerte de Montserrat, en 1599. Páez insistiría en su proyecto y, en 1603, regresaría a Etiopía donde, tras un año de actividad educativa y misionera, obtendría acceso a la corte del emperador. La pericia dialógica, profundo intelecto y actitud humilde de Páez lo acercaron a los mandatarios Za Denguel y, luego de su muerta en batalla, a Susinios. A decir de Ruiz de Santiago, la discusión, así como la práctica de la amistad, asemejan las misiones de Páez y Ricci:

... esta realidad humana tan profunda -la amistad- habría de conducir, al igual que en la vida de Matteo Ricci, a resultados magníficos. El Evangelio habría de ser predicado con base en hondos valores humanos, cultivados con sabiduría y profundidad ${ }^{36}$.

El camino misionero de Ricci fue espiritual, al tiempo que físico: caminará hacia el horizonte metafísico de una China cristiana y simultáneamente sus pies lo llevarán a Beijing, centro neurálgico y asiento del poder político chino. De la misma forma como enfrentará tropiezos espirituales - uno de los más emotivos será la llamada Controversia sobre los Ritos Chinos-, su paso físico por China tendrá, como le sucedió a Páez en su primera incursión en tierras etíopes, un revés: poco antes de finalizar el viaje hacia Beijing, Ricci será detenido y hecho prisionero por el eunuco Ma Tang durante varios meses. Será necesaria la intervención del propio Emperador Wanli para liberar al misionero y permitir su entrada en la ciudad imperial, en enero de 1601 .

Matteo Ricci nació en Macerata, Italia, en 1552. Antes de cumplir diecinueve años ya se contaba dentro de las filas de la recién fundada Compañía de Jesús de Ignacio de Loyola. Tras completar su educación en Roma, India y Macao, Ricci ingresó al imperio Chino de la dinastía Ming en 1583, estableciendo su primera residencia

\footnotetext{
35 Ruiz de Santiago, 2012, 108.

36 Ruiz de Santiago, 2012, 112.
} 
en Zhaoqing, en la provincia de Cantón. Inicialmente Ricci y su compañero, Michele Ruggieri, desoyeron el consejo de su superior, Alessandro Valignano, prefiriendo vestirse como monjes budistas (bonzos) -según el consejo del gobernador Wang Pan-a fin de aparecer ante la sociedad china como hombres de religión ${ }^{37}$. Al poco tiempo cayeron en cuenta de que, dentro de la sociedad china, los monjes budistas eran vistos con desconfianza y sospecha por la clase educada ${ }^{38}$. Ricci, asiduo estudioso no sólo de teología y cuestiones religiosas, sino ampliamente versado en matemáticas, gramática, mnemotecnia ${ }^{39}$ y cartografía, comprendió que la estrategia había sido incorrecta. La realidad sociopolítica China ofrecía la explicación: la clase dirigente en la dinastía Ming (1368-644) estaba dominada por el neoconfucianismo, caracterizado por su dura crítica al budismo.

Contra la tendencia budista al aislamiento y el quietismo, Confucio aparece como un sabio fuertemente interesado en el carácter social de la vida, misma que, de acuerdo con Chang Wing-Tsit, encuentra en el concepto de yen una de sus definiciones más acabadas. Para Confucio, yen «consiste en gobernarse y restaurar el orden moral $(l i) »^{40}$. Confucio abogaba por un «hombre superior» cuya virtud lo elevase por encima de los otros, distinguiéndose por el equilibrio, autosuficiencia, seriedad, minuciosidad, honestidad, amor a la verdad, pureza de pensamiento y acción, hospitalidad, rectitud, prudencia, serenidad, valentía, dignidad, firmeza, benevolencia, amplitud de miras, caridad y moderación, características todas que pueden resumirse en una «regla de oro»: «Cuando alguien cultiva al máximo las capacidades de su naturaleza, y las ejercita bajo el principio de reciprocidad, no está lejos del camino. Lo que no quieras que te hagan, no lo hagas a los otros» ${ }^{41}$. Confucio no creó una religión, sino que ofreció pautas éticas a través de las cuales construir al hombre virtuoso. En esto, el sabio chino se encuentra más cercano a Sócrates que a Buda y Jesucristo.

La primera cuestión que plantea la táctica de Ricci se enmarca en el nivel motivacional: ¿fue su profundización del confucianismo sólo una estrategia divisada utilitariamente, esto es, con vistas a maximizar la eficacia del proyecto evangélico, o, por el contrario, Ricci encontró en Confucio una puerta que ofrecía algo más que camuflaje? ¿Era el interés del jesuita por el idioma, cultura y ciencia chinos apenas una coartada para encubrir un proyecto de dominación religiosa y cultural? $\mathrm{O}$, por el contrario, ¿se involucró Ricci a tal grado en la cosmovisión china que perdió de vista su misión apostólica?

\footnotetext{
37 Clarke 2011, 12.

38 «Desde el advenimiento del budismo a China, los filósofos lo han criticado mucho. Sin embargo, el ataque decisivo lo descargaron los neoconfucianos... Consideraban insostenible la teoría budista de la renunciación, porque insistían en que, aun en el caso de que un hombre abandonara a su familia, nunca podría escapar a la sociedad mientras pisase la tierra... Criticaban a los budistas que tomaran equivocadamente la realidad concreta por un vacío... Encontraban que el Vacío budista se fundaba realmente en el fracaso para comprender la Razón de las cosas». Filosofía del Oriente, (Chang Wing-Tsit, 1954, 104).

39 Spence, 1985.

${ }^{40}$ Chang Wing-Tsit, 1954, 68.

41 Confucio, Doctrine of the Mean, (c.xiii, v.3), citado en Dawson, 1915, 6.
} 
Comencemos diciendo que varios académicos plantean, sin visos de duda, que Ricci «nunca abandonó la búsqueda de llegar a sus interlocutores por los caminos doctrinales de la fe» ${ }^{42}$, entendiendo que, a partir del diálogo con los intelectuales chinos sería posible «abrir paso a lo que es específicamente cristiano» ${ }^{43}$. Incluso $\mathrm{Yu}$ Liu, claramente crítico de la empresa ricciana, coincidirá con Gernet en que «Ricci estaba animado por una «voluntad de conquista y proselitismo» ${ }^{44}$. Aceptando, pues, la sinceridad de Ricci respecto de su misión evangélica, me parece pertinente centrar la cuestión primordial en su convencimiento -surgido, quizá, en el mismo texto evangélico ${ }^{45}$ - de que el mensaje cristiano puede (¿debe?) abrazar, fecundándolo, el contexto cultural en que se presenta ${ }^{46}$.

Ricci no fue el primer misionero en entrar a China, pero sí el más exitoso. Ana Hosne define su estrategia como cristianismo en clave confuciana; Lake Coreth, como apostolado indirecto.

Para Ignacio de Loyola, «la uniformidad con la Iglesia católica debe hacerse con dulzura y sin hacer violencia sobre esas almas habituadas a otro género de vida» ${ }^{47}$. Ricci acató la directriz ignaciana a través del reconocimiento de lo específicamente chino, esto es, fundando un nuevo espacio simbólico donde la riqueza de la cultura china fuera alumbrada por el mensaje cristiano. Lo «uno», de esta manera, no surge sino hasta el final del proceso misionero, es decir, en la conversión: la persona es tomada en su especificidad más radical y, sin dislocarla, es insertada en un horizonte que redefine dicha especificidad a través de un dramático giro en el sentido existencial. Así, el monumental Mappamondo de Ricci que asombró a los chinos, lo mismo que su traducción de los Elementos de Geometría de Euclides, su Xiguo Jifa sobre mnemotecnia que ofrece a los hijos del gobernador Jiangxi, así como su magistral estudio De Amicitia (Jiayou Lun), forman parte de un diálogo intercultural que tendía, en última instancia, a la conversión.

Ricci encontrará la filosofía de Confucio más cercana al cristianismo y reafirmará su desprecio por el budismo, caracterizado por «la omnipresencia de los ídolos... que no sería otra cosa que la encarnación de la idolatría en China, a la que Ricci asimiló también a los daoístas» ${ }^{48}$. Para Ricci, la mayor compatibilidad entre confucianismo y cristianismo residía en que los antiguos confucianos habían adorado a un $\operatorname{Dios}^{49}$ en la figura de Shang di, o «Señor de lo Alto». Esta confesión monoteísta acercaba a cris-

\footnotetext{
42 Hosne, 2009, 15.

43 Ruiz de Santiago, 2012, 126.

44 Yu Liu, 2008, 467.

${ }^{45}$ Cfr. Jn 3:8, Hch 2:4.

${ }^{46}$ Cfr. Hch 2:14-41, Hch 17:22-33. Pedro y Pablo son paradigmas de dos modelos de evangelización que, no obstante su diferencia, encuentran unidad en el mensaje de Cristo.

${ }^{47}$ Ruiz de Santiago, 2012, 110.

48 Hosne, 2009, 22.

${ }^{49}$ Yu Liu estima que Ricci confundió la idea de divinidad confuciana, asemejándola injustificadamente al Dios cristiano: «the notion of divinity was never more than what Chan terms "a self-existent moral law"... the Confucian belief in tian or heaven is not equivalent to European theism, because it is against any anthropomorphized idea of deity». Yu Liu, 2008, 474-475.
} 
tianos y confucianos y proveía, además, un terreno común a partir del cual construir el proyecto evangelizador. Los jesuitas, no obstante, utilizaron el nombre Tianzhu, o «Señor del Cielo» para referirse al Dios del catolicismo, indicio de su voluntad de insistir en la novedad del cristianismo al tiempo que rechazar cualquier disolución del credo cristiano en el confuciano.

Su De Amicitia (Jiaoyou Lun), así como sus Veinticinco Sentencias (Ershiwu yan) constituyen los mejores ejemplos de esta estrategia. Ambos son elaborados a partir del conocimiento ricciano de la tradición grecolatina. El primero, inspirado en las Sententiae et Exempla ${ }^{50}$ del latinista Andreas Eborenis, echa mano de la sabiduría occidental para discutir uno de los temas de moda en la intelectualidad china de la época: la amistad. El segundo, como muestra el jesuita Christopher Spalatin en su disertación doctoral «es una traducción cuidadosamente editada y seleccionada del Enquiridión de Epicteto» ${ }^{51}$. Las temáticas de la virtud y la amistad tenían, en la China Ming, una importancia capital, especialmente en los círculos intelectuales. No hay duda que Ricci pretendía darse a conocer como un sabio, ampliamente versado en estas materias, lo que le permitiría el soñado acercamiento a la corte imperial.

Ahora bien, dichos documentos no abandonan el proyecto capital de la evangelización. Analicemos la sentencia 50 del De Amicitia:

La amistad prevalece sobre los miembros de la familia en un solo aspecto: es posible que los familiares no se amen uno a otro. Pero esto no sucede entre amigos. Si alguien de la familia no ama a otro, la relación de parentesco subsiste. Pero, a menos que exista amor entre amigos, ¿puede subsistir el principio esencial de la amistad? ${ }^{52}$.

Para Hosne, Ricci «está impugnando uno de los pilares sobre los que descansa todo el sistema social chino: la piedad filial» ${ }^{53}$. Me parece posible una interpretación complementaria basada en el Evangelio de Mateo: mientras Jesús debatía con fariseos y escribas, «alguien» le hace saber que su madre y hermanos le esperan afuera para hablarle. Jesús responde enigmáticamente: «¿Quién es mi madre y quiénes son mis hermanos?... Éstos son mi madre y mis hermanos. Porque todo el que hace la voluntad de mi Padre que está en el cielo, ése es mi hermano, mi hermana y mi madre» (Mt 12:50). Dos aspectos me parecen destacables. En primer lugar, la personalidad ignota del interpelante de Jesús otorga a la respuesta una fuerza peculiar: no está dirigida a un grupo particular -lo que obligaría exégesis ulteriores para determinar su valor en sí misma-; el recurso literario del evangelista otorga a las palabras de Jesús una peculiar fragancia, de suerte que el lector se siente tentado a tomarlas en su

\footnotetext{
50 Hosne, 2009, 14.

51 Spalatin, 1975, 8 .

52 Ricci, 2009, 111.

53 Hosne, 2009, 32.
} 
mayor radicalismo. La interrupción surge desde un anonimato que, lejos de remitir a la «masa», abraza a la humanidad toda, al hombre en cuanto tal que interroga a Jesucristo sobre el delicado aspecto de su origen $(C f \mathrm{Mc} 6: 3$, Jn 18:33). Las palabras del evangelista pueden entenderse como una pregunta que el género humano lanza a aquel que se ha presentado como «mesías».

Esta «sinceridad», en segundo término, no debe conducir a una lectura simplista tal que ofrezca a un Jesús renuente a reconocer su filiación. El mensaje no se formula como crítica a la consanguinidad, sino como su superación a través de una nueva espiritualidad. El mismo sentido tienen, me parece, las palabras de Cristo dirigidas a Juan y a su madre en la cruz (Jn 19: 26-27), así como su sentencia sobre la paz (Lc 12:51-53).

Las palabras de Jesús no pretenden bombardear las estructuras de la sociabilidad humana, sino espiritualizarlas. La estrategia parece la siguiente: tomar un concepto «ordinario», como la relación filial, e insertarlo en la nueva metafísica abierta por la revelación trinitaria ${ }^{54}$ fundada en el amor (Jn 15:9). Así, la filiación divina (1Jn 3:1) se hace comprensible como mutación, como perfeccionamiento del elemento humano: el amor entre padre e hijo es llevado, en el mensaje cristiano, a su última expresión en la relación entre hombre(Hijo) y Dios(Padre) mediada por la figura del Hijo. Esta mutación, por último, está íntimamente ligada a la idea cristiana de «conversión» (Gal 2:20).

Podemos volver ahora a la reflexión sobre el texto ricciano formulando la posibilidad de que, en efecto, dicha máxima pretenda no sólo integrar al jesuita en la discusión académica china sobre la amistad, sino introducir una de las estructuras primordiales para la evangelización, a saber, la espiritualización de la naturaleza humana. Basta recordar el texto joánico: «ya no los llamo servidores... yo los llamo amigos» (Jn 15:15), para comprender que el «ataque» de Ricci a las estructuras tradicionales de autoridad se encuentra alineado con esta espiritualización. El concepto de «amistad» adquiere, así, una nueva dimensión espiritual que, lejos de dinamitar las estructuras tradicionales, las perfecciona direccionándolas al encuentro con lo divino.

Digamos, finalmente, que ejemplos similares al anterior podrían desarrollarse, mostrando su clave cristiana: en la sentencia 12 del tratado, a la pregunta; « ¿No es esto evidencia de que el mundo es débil en bondad y fuerte en maldad?», puede corresponderle la sentencia: «los hijos de este mundo son más astutos en sus tratos con los demás que los hijos de la luz» (Lc 16:8); la sentencia 29, «los bienes materiales de los amigos son todos tenidos en común», se corresponde con: «nadie consideraba sus bienes como propios, sino que todo era común entre ellos» (Hch 4:32); finalmente, el comentario a la sentencia 31 dicta: «si un amigo comete una falta, y ésta es menor, uno debe tolerarla; si un amigo hace algo moralmente malo, se trata entonces

\footnotetext{
54 «[E]1 Dios real es, por su esencia, un total «Ser-para» (el Padre), «Ser-desde» (el Hijo) y «Ser-con» (el Espíritu santo. Ahora bien, el hombre es precisamente imagen y semejanza de Dios porque el «desde», el «con» y el «para» constituyen la figura antropológica fundamental» (Ratzinger, 2005, 214).
} 
de un asunto serio, y uno debe descartar a dicho amigo» se corresponde con el proceso neotestamentario de corrección fraterna (Mt 18:15-17) ${ }^{55 .}$

\section{DESPUÉS DEL CONCILIO VATICANO II: RATZINGER Y TAYLOR}

A lo largo de esta reflexión he comparado dos perspectivas distintas de evangelización que emergen de posiciones epistemológicas igualmente dispares. La primera se apropió de la doctrina del derecho natural para justificar la conquista, política y espiritual, como solución a la barbarie y herejía de los indios. Se creyó justificada la misión de «obligar al infiel a ser libre», reduciendo su libertad a la aceptación, sincera o no, de un proyecto que le era ajeno, cuando no absolutamente ininteligible. Esta conceptualización del «otro», así como de la estrategia de conquista y evangelización, cobra sentido en el proyecto sociopolítico que Taylor denomina Cristiandad.

El proyecto de Ricci, por su parte, muestra conceptualizaciones y estrategias completamente distintas, que se colocan en las antípodas de la Cristiandad. Al estar cerrada la posibilidad de dominio, el jesuita debió adoptar nuevas estrategias, encontrando en el pensamiento confuciano algo más que su boleto de entrada a la corte imperial: halló un desarrollo intelectual valioso en sí mismo, que le permitiría entender su misión desde el diálogo cultural, abriendo un puente reflexivo que hiciera brotar aquellos elementos cristianos que estaban vivos -oculta e, incluso, inconscientemente- en la cultura china.

Así, mientras que la evangelización española se inserta en el gran proyecto sociopolítico y religioso llamado «Cristiandad», la misión jesuita en China es signo temprano de una nueva actitud en la autocomprensión del catolicismo, a saber, aquélla erigida sobre el reconocimiento de la inevitable diversidad ${ }^{56}$ en el hombre libre y la necesidad de entender el proyecto católico a la luz del aquí ahora particular, encontrando una voz que, sin caer en perspectivas relativistas, se inserte armónicamente en el coro de la humanidad.

En esta última sección discuto el pensamiento de Charles Taylor y Joseph Ratzinger, a través de los cuales, me parece, es posible comprender -con el primero- la distinción entre los proyectos de evangelización comentados en las secciones anteriores, así como -con el segundo- ahondar en el deslizamiento epistemológico a través del

\footnotetext{
55 Soy consciente de que la sentencia 52-«ser amigo de los amigos de tus amigos y enemigo de los enemigos de tus amigos es la base para una profunda amistad»-choca abiertamente con la doctrina cristiana. Ricci hace a un lado la sentencia: «Yo les digo, amen a sus enemigos, rueguen por sus perseguidores... Si ustedes aman solamente a quienes los aman, ¿qué recompensa merecen?» (Mt 5:44-46). Me parece que Ricci adopta aquí una postura claramente confuciana. Dawson reporta que Confucio fue cuestionado respecto al dicho de Lao Tse-《¡Ama a tus enemigos!»-: «¿Qué dices respecto del principio de que la injuria debe recompensarse con amabilidad?” El Maestro dijo: “¿Con qué recompensarán, entonces, la amabilidad?”» (Dawson, 1915, 124).

56 Entiendo el término a partir de Rawls $(2005,4)$ : el pluralismo es «the inevitable long-run result of the powers of human reason at work within the background of enduring free institutions».
} 
cual los proyectos de dominación religiosa a través del matrimonio entre la fe y una forma social determinada se vuelven absolutamente indefendibles.

En su conferencia, "A Catholic Modernity», Charles Taylor ofrece una evaluación crítica respecto de la modernidad y, particularmente, respecto de la forma como en ella se «entremezclan juntos tanto desarrollos auténticos del Evangelio... como una clausura de Dios que niega dicha palabra» ${ }^{57}$. A la luz de estos desarrollos históricos, Taylor recomienda al católico contemporáneo una estrategia de discernimiento similar a la que Matteo Ricci llevó a cabo en China ${ }^{58}$.

Taylor considera la irrupción de la modernidad como un acontecimiento necesario y positivo en la historia de la fe católica: gracias a ella fue posible romper el matrimonio entre fe y política, entre un determinado credo religioso y una forma social sancionada por la amalgama de la espada y el báculo. La Cristiandad (Christendom) se apresuró a hacer del poder político un aliado permanente, resbalando muy pronto en la arena movediza de la coerción como herramienta evangelizadora.

Por supuesto, esta misma modernidad, que obligó el divorcio entre fe y poder y abrió para el cristianismo la posibilidad de una revalorización de su núcleo auténtico, no está libre de demonios propios. Taylor considera tres «malestares» 59 fundamentales que aquejan a la modernidad: (1) El individualismo que, en el marco del «desencantamiento del mundo» ${ }^{60}$, ha disuelto los horizontes significativos tradicionales, es decir, las grandes narrativas a través de las cuales el individuo generaba, otrora, sentido en su vida. (2) La primacía de la racionalidad instrumental, definida por la utilidad, el análisis costo-beneficio y la aplicación de medios a determinados fines, que amenaza con imponer su lógica a la totalidad de lo humano, obligando al espectro de las manifestaciones humanas a verterse dentro de su filtro ${ }^{61}$. (3) En el seno compartido del individualismo y la racionalidad instrumental se gesta, finalmente, el peligro descrito por Alexis de Tocqueville en Democracia en América. La exacerbación del principio de libertad trae consigo un desgastamiento de su contraparte, el principio de igualdad, provocando un desequilibrio antidemocrático:

Esto inaugura el peligro de un despotismo nuevo y específicamente moderno, que Tocqueville llama despotismo «suave». No será una tiranía de terror y opresión como en los viejos tiempos. El gobierno será apacible y paternalista. Guardará, inclusive, las formas democráticas, con elecciones periódicas. Pero de hecho, todo será llevado a cabo con un «inmenso poder tutelar» sobre el que la gente tendrá muy poco control. La única defensa contra esto, piensa Tocqueville, es una vigo-

\footnotetext{
57 Taylor, 1999, 16.

58 "... to try to do for our time and place what Matteo Ricci was striving to do four centuries ago in China», Taylor, 1999, 15.

59 Taylor, 2003. Capítulo 1.

60 Ver Gauchet, 1999.

${ }^{61}$ La crítica de Heidegger a la técnica explica la dominación del hombre sobre la naturaleza por la aplicación de una fuerza que reduce lo natural a catálogo de existencias y termina por extenderse a los individuos, que son convertidos, ellos mismos, en stock. Ver, Heidegger, 1977.
} 
rosa cultura política donde la participación es valorada... Pero el atomismo del individuo absorto en sí mismo milita contra esto ${ }^{62}$.

¿Cómo evaluar, pues, una modernidad benéfica, por un lado, saludable para la reconstrucción del espíritu cristiano, y peligrosa, por otro, capaz de transformar la democracia en silencioso yugo? Taylor ofrece una respuesta en dos niveles.

Desde la perspectiva de la modernidad, Taylor considera que, si bien los tres malestares antes descritos representan considerables amenazas, detrás de ellos o, mejor dicho, en su anverso, trasluce un principio ético que hace de la modernidad un valioso proyecto por el que vale la pena luchar. La autenticidad es, para Taylor, el principio ético a través del cual emerge la sociedad moderna. El hombre auténtico de la modernidad sustituye al hombre obediente de otras épocas. La autenticidad, en tanto fidelidad al propio yo, tiene el doble efecto de difuminar las fronteras y los límites, complicando los tradicionales binomios bondad-maldad, justicia-injusticia; pero, al mismo tiempo, recupera para el individuo el control y la decisión sobre sí mismo, otorgándole valor a sus obras en tanto suyas, esto es, en tanto expresión responsable del individuo. La pregunta, en este caso, es: ¿qué valor tiene un hombre que obedece por miedo o ignorancia, en contraste con uno que piensa, analiza, medita y decide determinado curso de acción?

El catolicismo, por su parte, encuentra en la autenticidad el mismo aliento. Tras su análisis de la modernidad, Taylor recomienda al católico seguir la senda de la «diferencia». Tomando la doctrina trinitaria como ejemplo por excelencia, el filósofo canadiense estima que sólo desde el reconocimiento de la diversidad es posible arribar a una promoción adecuada de lo cristiano: «parece que la vida de Dios mismo, entendida como trinitaria, es ya una apertura de este tipo. La diversidad humana es parte de la forma en que hemos sido creados a imagen de Diosı ${ }^{63}$. Esto no implica una rendición del cristianismo al credo moderno. Taylor es cuidadoso de no promover una modernidad católica, «si por ella comenzamos... a vernos como "católicos completos", de una vez y para siempre» ${ }^{64}$. Al contrario, su perspectiva consiste, en tanto inspirada por la empresa ricciana, en un trabajo de discernimiento del lugar que ocupa el catolicismo en nuestros días, del significado que tiene «ser cristiano» aquí y ahora, a partir del descubrimiento de los encuentros y desencuentros entre la cultura actual y la doctrina católica.

Contra los peligros de una modernidad exacerbada, a la que llama «humanismo exclusivo», Taylor propone este nuevo catolicismo que se entiende a sí mismo desde el amor y la compasión incondicional, por un lado, y la internalización y promoción del significado auténtico de ser imagen de Dios. De esta forma, la figura de Ricci emerge, en el pensamiento de Taylor, como premonición de un renovado catolicismo que, arropado bajo una teología trinitaria entendida como paradigma de la unidad a

\footnotetext{
62 Taylor, 2003, 9. La traducción es mía para todas las citas de Taylor.

63 Taylor, 1999, 14-15.

64 Taylor, 1999, 15.
} 
través de la diferencia, la revalorización de la autenticidad y el redescubrimiento del carácter dinámico del fenómeno religioso, debe buscarse una y otra vez en las distintas manifestaciones históricas para encontrar la particular tonalidad que debe adquirir aquello que la exhortación apostólica, Evangelii Gaudium, de Francisco, define como el «corazón del Evangelio», en cuyo núcleo resplandece «la belleza del amor salvífico de Dios manifestado en Jesucristo muerto y resucitado» ${ }^{65}$.

El pensamiento de Joseph Ratzinger ${ }^{66}$ complementa y enriquece la división tayloriana antes discutida. Dos aspectos resultan importantes: (1) su comprensión del Concilio Vaticano II como momento de escisión entre dos formas de lo católico; y (2) su discusión epistemológica sobre la fe, por medio de la cual este catolicismo «posconciliar» es posible.

A grandes rasgos, me parece que Ratzinger suscribe la evaluación tayloriana de la Cristiandad, observando él también una mutación de la autoconciencia cristiana ${ }^{67}$, que va de la autoridad a la conciencia, de la imposición dogmática a la responsabilidad individual, del «obligar a ser libres» al encuentro personal con un Dios vivo. Así, existen para el teólogo alemán dos concepciones de lo católico: «un entendimiento renovado de su esencia, que despliega la fe cristiana desde el fondo de la libertad y como principio de la libertad, y un anticuado modo "preconciliar", que subordina la existencia cristiana a la autoridad, la cual regula la vida hasta en sus más íntimos recintos tratando de mantener su poder sobre los hombres ${ }^{68}$. La continuidad entre el pensamiento tayloriano y ratzingereano es clara: la «moral de la autoridad» necesita el auxilio de los instrumentos sociales y políticos adecuados para mantenerse hegemónica, mientras que la «moral de la conciencia» coexiste, bajo la libertad, en una diversidad de ambientes y contextos ${ }^{69}$.

La Iglesia Católica afirma que Dios puede ser conocido por la luz de la razón humana: «a través de las cosas creadas... el hombre tiene esta capacidad porque ha sido creado a "imagen de Dios" $\gg{ }^{70}$. Comprender este artículo implica determinar los alcances de la razón humana, el significado de «las cosas», así como definir con

65 Francisco, 2013, §36.

${ }^{66} \mathrm{Al}$ hablar del pensamiento «ratzingereano» tengo en mente a un «primer Ratzinger», esto es, al teólogo y no al funcionario de Roma. Creo que existen dificultades importantes en la integración de ambos momentos, lo que no pretende acusar un viraje en el pensamiento del alemán, ni mucho menos una renuncia a sus más íntimos compromisos intelectuales. Más bien parece que el «Ratzinger intelectual» está en uso de su razón pública, en sentido kantiano, mientras que el «Ratzinger funcionario de Roma» utiliza, en cambio, la razón privada.

${ }^{67}$ La forma como se operó esta transformación de la empresa católica exigiría un análisis que excede el objetivo de este documento, y que llevaría a una reflexión sobre el progresivo decaimiento del poder papal, la emancipación de los individuos bajo el influjo de la ilustración o el romanticismo, y la amenaza que el individualismo supuso a las doctrinas comunitarias (Iglesia como koinonia).

${ }^{68}$ Ratzinger, 2005, 43-44.

69 Podría argumentarse, ciertamente, que la Iglesia Católica no ha abandonado una posición de autoridad respecto al dogma. Aceptando la validez de esta premisa, cabe distinguir entre «artículos de fe» y «artículos de moralidad». Mientras que los primeros sólo pueden ser «conocidos» mediante revelación divina - de la cual la Iglesia Católica, efectivamente, se manifiesta como depositaria única- los segundos se refieren a lo que Kant denomina razón práctica. La transición de la que habla Ratzinger es, indudablemente, referida a estos últimos.

70 Catecismo de la Iglesia Católica $\$ 36$. 
claridad a qué tipo de «capacidad» nos referimos. A este respecto, la Constitución Dogmática del Concilio Vaticano I, Deus Filius (1870), ofrece algunas reflexiones importantes: (1) que existen misterios que, a menos que medie una revelación divina, están vetados a la razón humana; (2) que los misterios divinos se encuentran «cubiertos por un velo», de forma tal que en la vida mortal «caminamos con la fe, no con la vista»; y (3) que los dos aspectos anteriores no pueden implicar una contradicción real entre fe y razón.

Cuando volteamos la vista, empero, a la Constitución Dogmática del Concilio Vaticano II, Dei Verbum (§6), encontramos la siguiente redacción:

Confiesa el Santo Concilio «que Dios, principio y fin de todas las cosas, puede ser conocido con seguridad por la luz natural de la razón humana, partiendo de las criaturas»; pero enseña que hay que atribuir a Su revelación «el que todo lo divino que por su naturaleza no sea inaccesible a la razón humana lo pueden conocer todos fácilmente, con certeza y sin error alguno, incluso en la condición presente del género humano» (Las cursivas son mías).

¿Cómo hacer compatibles la existencia de un velo que oscurece los misterios divinos, y los adjetivos «seguridad», «facilidad» y «certeza», predicados respecto del conocimiento de Dios? La respuesta, a mi parecer, se encuentra en el pensamiento ratzingereano.

En Introducción al cristianismo, Ratzinger afirma:

Nadie puede poner a Dios y su reino encima de la mesa, y el creyente, por supuesto, tampoco. El que no cree puede sentirse seguro en su incredulidad, pero siempre le atormenta la sospecha de que «quizá sea verdad». El «quizá» es siempre una tentación ineludible a la que nadie puede sustraerse; al rechazarla, se da uno cuenta de que la fe no puede rechazarse... tanto el creyente como el no-creyente participan, cada uno a su modo, en la duda y en la fe, siempre y cuando no se oculten a sí mismos y a la verdad de su ser. Nadie puede sustraerse totalmente a la duda o a la fe. Para uno la fe estará presente a pesar de la duda, para el otro mediante la duda o en forma de duda... Quizá justamente por eso, la duda, que impide que ambos se cierren herméticamente en lo suyo, pueda convertirse ella misma en un lugar de comunicación ${ }^{71}$.

La clave epistemológica en Ratzinger es, por supuesto, la $d u d a$ como elemento indispensable para comprender la distancia entre Dios y el hombre, así como los límites de la racionalidad humana. Esta duda surge a partir del abismo entre Creador y criatura, que San Agustín captura en su frase: «si enim comprehendis, non est Deus» y que el teólogo alemán explica en los siguientes términos:

71 Ratzinger, 2001, 45. 
...entre Dios y el hombre hay un abismo infinito; porque el hombre ha sido creado de tal manera que sus ojos sólo pueden ver lo que no es Dios, y Dios es, por tanto, el esencialmente invisible para los hombres, el que cae y siempre caerá fuera del campo visual humano... Dios es aquel que queda esencialmente fuera de nuestro campo visual, por mucho que se extiendan sus límites ${ }^{72}$.

Esta idea se encuentra en línea con la perspectiva conciliar por la que el hombre, en la oscuridad de lo divino, «ve» con la fe. La oscuridad, por su parte, remite a la epistemología kantiana ${ }^{73}$, pero la complementa con una fe capaz de «ver» lo «invisible» ${ }^{74}$. La fe, para Ratzinger, no es primordialmente un sistema de conocimiento alternativo a la razón -aunque indudablemente abre horizontes de un «conocer» auténtico-, sino «una forma primaria de situarse ante el ser, la existencia, lo propio y todo lo real» ${ }^{75}$. Con esta idea tenemos, ya, el cuadro completo del modelo posconciliar ratzingereano, que podemos resumir en los siguientes términos: la constatación de los límites de la razón humana obligan el reconocimiento de la $d u d a$ como horizonte inescapable en la búsqueda de Dios, así como la confirmación de la fe como decisión existencial que abre una nueva dimensión del «conocer» radicalmente distinta a aquélla inaugurada por la razón.

Resta únicamente explicar el sentido de los adjetivos conciliares de «seguridad», «facilidad» y «certeza». Me parece que, en primer lugar, debe quedar claro que estos adjetivos no pueden referirse a la función racional -entendida, nuevamente, en el sentido kantiano de razón pura. En segundo lugar, estas palabras cobran sentido cuando se utilizan como predicados de la fe: el encuentro del hombre con Dios implica, para la fe, una rotación del punto de vista existencial que permite «ver» con ojos nuevos. Los propios adjetivos son transformados en este giro existencial, de modo que la seguridad y certeza se anidan en el espíritu ${ }^{76}$, más que en un procedimiento empírico comprobable y verificable.

En resumidas cuentas, Ratzinger defiende el cambio en el eje de rotación del catolicismo desde la autoridad hacia la conciencia, apoyando dicha modificación, indudablemente, en una concepción epistemológica que reconoce la ineluctabilidad de la duda, en creyentes y no creyentes, misma que permite abrir un espacio de comunicación que, en sus propias palabras, «impide que ambos se cierren herméticamente en lo suyo». La resonancia de estas ideas con el proyecto ricciano son tan grandes como lo es la imposibilidad de conciliar esta perspectiva con el proyecto de la «Cristiandad».

\footnotetext{
72 Ratzinger, 2001, p. 48.

73 Kant, A742/B770, p.649.

74 «La última certeza sobre la que basamos toda nuestra existencia nos viene dada por la fe», Ratzinger, $2011,128$.

75 Ratzinger, 2001, 48.

${ }^{76}$ La reflexión de Kołakowski $(2002,101)$, sobre la experiencia mística apunta en este mismo sentido: «La misma expresión "experiencia de lo Eterno e Infinito" indica la imposibilidad fundamental de describir adecuadamente la unión mística: ¿cómo puede, en efecto, lo Eterno e Infinito "darse” auténticamente en actos que no implican nociones abstractas? Esta experiencia es "directa"... y sin embargo, no es en absoluto sensorial... Ningún místico ha intentado "demostrar" la existencia de Dios: para él eso sería como intentar demostrar que la miel es dulce o quizá que el agua es húmeda».
} 


\section{BIBLIOGRAFÍA}

C. Alvear Acevedo, Medio milenio de evangelización, México, 1992.

Aristóteles, La política, (trad. esp.), Madrid, 2004.

J. Clark (ed.), Binding Friendship. Ricci, China, and Jesuit Cultural Learnings, Chestnut Hill, 2011.

Congregación para la Doctrina de la Fe, Catecismo de la Iglesia Católica (trad. esp.), Ciudad del Vaticano, 1997.

M. M. Dawson, The ethics of Confucious. The saying of the master and the disciples upon the conduct of «the superior man», New York, 1915.

T. De Aquino, Suma teológica (trad. esp.), Madrid, 1959.

Erasmus, The complaint of Peace, Chicago, 1917, https://archive.org/details/complaintofpeace 017046mbp [acceso: 23.06.2014]

A. Espigares Pinilla, «El enfrentamiento de Erasmo en el Gonsalus de Ginés de Sepúlveda», Cuadernos de Filología Clásica. Estudios Latinos 4 (1993) 181-190.

Francisco, Evangelii Gaudium (trad. esp.), Ciudad del Vaticano, 2013.

M. Gauchet, The disenchantment of the world (trad. ing.), Princeton, 1999.

A. De la Hera, Los derechos espirituales y temporales de los naturales del nuevo mundo, México, 1992.

M. Heidegger, The question concerning technology (trad. ing.), New York, 1977.

A. C. Hosne, «La amistad virtuosa como mandato del señor de lo alto (Shang Di). Reflexiones en torno al tratado De amicitia (Jiayou Lun) (1595) del jesuita Matteo Ricci», Eadem Utraque Europa 9 (2009) 11-43.

I. Kant, Crítica de la Razón Pura, México, 2009 (reimp. México, 2011).

-, Filosofía de la historia, México, $1979^{2}$.

L. Kołakowski, Si Dios no existe..., (trad. esp.), Madrid, 2002.

B. de Las Casas, Los indios de México y la Nueva España, México, 1966.

—, Historia de las Indias, México, 1951.

—, Brevísima relación de la destrucción de las Indias, México, 1941.

Y. Liu, «The intricacies of acommodation: the proselytizing strategy of Matteo Ricci», $J$. World Hist. 4 (2008) 465-487.

M. Luther, Address to the nobility of the German Nation respecting the reformation of the Christian State, New York, 1520 (trad. ing.) http://www.fordham.edu/halsall/mod/luthernobility.asp [acceso 23.06.2014].

A. Maestre Sánchez, «'Todas las gentes del mundo son hombres’. El gran debate entre Fray Bartolomé de las Casas (1474-1566) y Juan Ginés de Sepúlveda (1490-1573)», Anales del Seminario de Historia de la Filosofía 21 (2004) 91-134.

A. Manero Salvador, «La controversia de Valladolid: España y el Análisis de la Legitimidad de la Conquista de América», Revista Electrónica Iberoamericana 2 (2009) 85-114.

Platón, La república (Diálogos Vol. 4) (trad. esp.), Madrid, 2003. 
J. Ratzinger, Jesús de Nazaret. Desde la entrada en Jerusalén hasta la Resurrección (trad. esp.), México, 2011.

—, Verdad, Valores, Poder (trad. esp.), Madrid, 2005.

—, Fe, Verdad y Tolerancia (trad. esp.), Salamanca, 2005a.

-, Introducción al Cristianismo (trad. esp.), Salamanca, 2001.L. Hanke, The Spanish struggle for justice and the Conquest of America, Philadelphia, 1948, https://archive.org/details/ spanishstrugglef006537mbp [acceso:23.06.2014].

—, El Papa Paulo III y los indios de América, México, 1992.

J. Rawls, Political Liberalism, New York, 2005.

M. Ricci, On Friendship. One hundred maxims for a Chinese Prince (trad. ing.), New York, 2009.

J. Ruiz de Santiago, «Matteo Ricci: Encuentro con China a través de la amistad. Aventuras jesuíticas a principios del siglo XVII», Estudios 10 (2012) 97-132, http://biblioteca.itam. mx/estudios/100-110/102/JaimeRuizdeSantiagoMatteoricci.pdf [acceso:23.06.2014].

B. de Sahagún, Historia General de las cosas de la Nueva España, México, 1999.

J. G. de Sepúlveda, Tratado sobre las justas causas de la guerra contra los indios, México, 1987.

C. Spalatin, S.J., Matteo Ricci's Use of Epictetus, Waegwan, 1975.

J. D. Spence, The memory palace of Matteo Ricci, New York, 1985.

Ch. Taylor, The Ethics of Authenticity, Cambridge, 2003.

—, A Catholic Modernity? Nueva York, 1999.

A. Velasco, «Alonso de la Veracruz. La tradición humanista republicana», Revista de la Universidad de México 46 (2007) 51-55.

F. de Vitoria, Relecciones, México, 1974.

Ch. Wing-Tsit et al, Filosofía del Oriente, México, 1954. 